
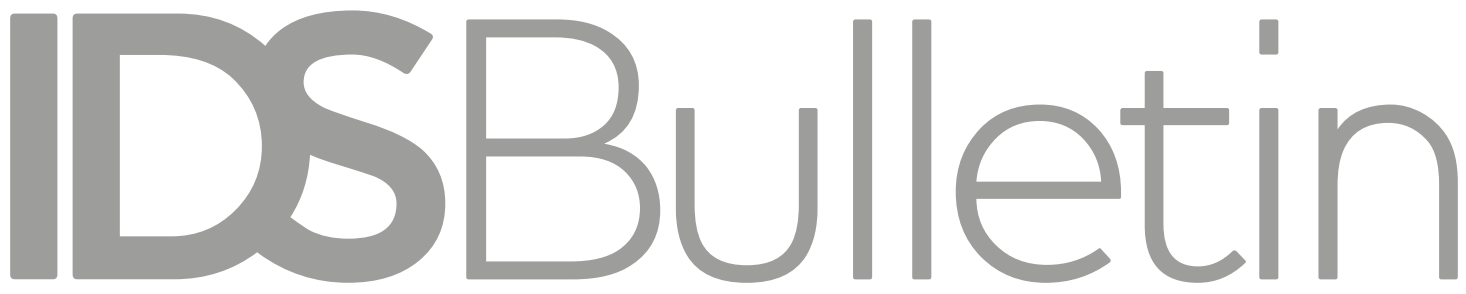

Transforming Development Knowledge

Volume 49 | Number 1 | January 2018

\title{
VALUE CHAINS FOR NUTRITION IN SOUTH ASIA: WHO DELIVERS, HOW, AND TO WHOM?
}

Editors Mar Maestre and Nigel Poole

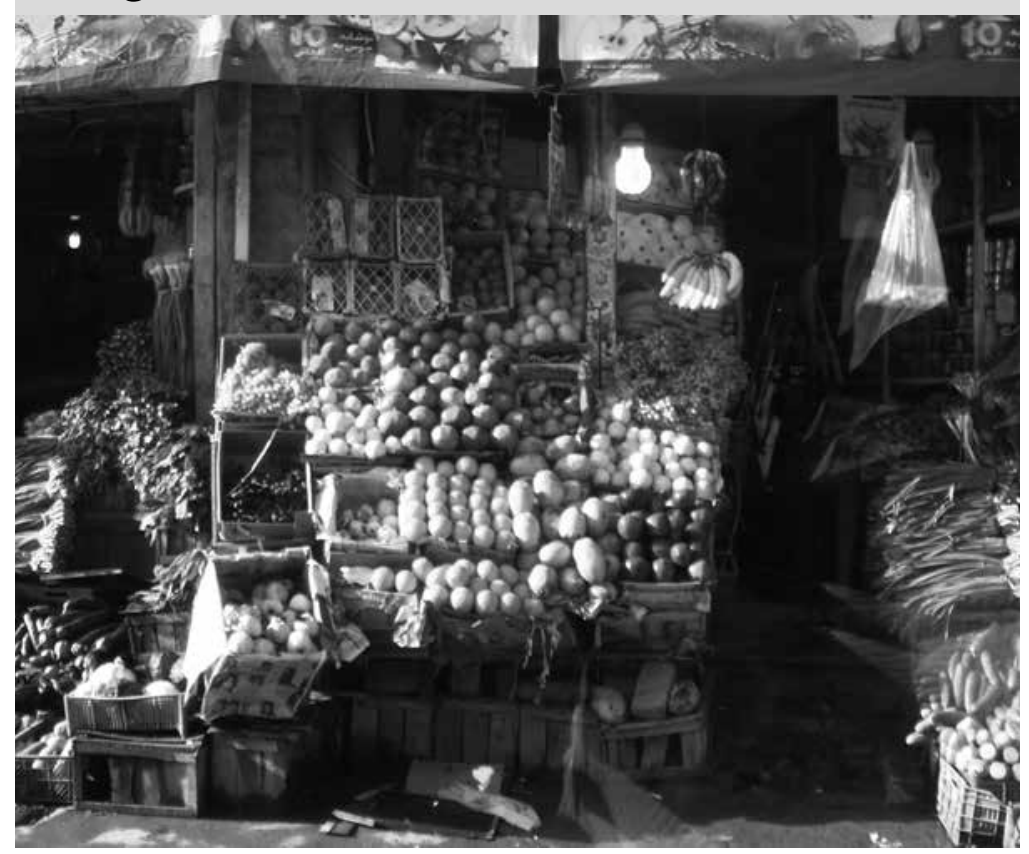


Notes on Contributors

Introduction: Value Chains for Nutrition in South Asia: Who Delivers, How, and to Whom?

Mar Maestre and Nigel Poole

Private Business-Driven Value Chains and Nutrition: Insights from India

Rohit Parasar and Bhavani RV

Business-Based Strategies for Improved Nutrition: The Case of Grameen Danone Foods

Jessica Agnew and Spencer Henson

Going Against the Grain of Optimism: Flour Fortification in Pakistan Natasha Ansari, Rashid Mehmood and Haris Gazdar

Food Distribution Value Chains under the Integrated Child Development Services

Bhavani RV and Rohit Parasar

'Milk for Milk, Uater for Uater': Analysing Pakistan's Dairy Innovation

Natasha Ansari, Rashid Mehmood and Haris Gazdar

Building Dairy Value Chains in Badakhshan, Afghanistan

Nigel Poole

A Study on Milk Value Chains for Poor People in Bangladesh

Md. Abid UI Kabir, Md. Sirajul Islam and Md. Hasib Reza

Focus on Gender, Context, and Evidence: CARE's Lessons Learned

Emily Janoch, Elly Kaganzi and Thomas Schaetzel

Glossary 


\title{
Going Against the Grain of Optimism: Flour Fortification in Pakistan
}

\author{
Natasha Ansari, Rashid Mehmood and Haris Gazdar
}

\begin{abstract}
Food fortification is a popular strategy for addressing 'hidden hunger', and staple foods are seen as promising, if unproven, vehicles for the delivery of essential micronutrients to poor people in developing countries. This article examines wheat flour fortification with iron in Pakistan as a case of technocratic optimism in the face of institutional constraints. An evaluative framework based on the analysis of entire value chains can provide a reality check on technocratic optimism. We find that poor people based their preferences for different types of flour on price as well as perceptions of nutritional value. Many of these flour types are not covered by fortification programmes. Fortification interventions, meanwhile, have attempted to leverage public-private partnerships in a segment of the wheat flour value chain which is beset with regulatory weakness. This article illustrates why technical interventions should support rather than ignore a broader agenda of reforms in food policy.
\end{abstract}

Keywords: wheat, wheat flour, grain, fortification, value chains, Pakistan, agriculture, nutrition, food systems, INGOs.

\section{Introduction}

Pakistan has high rates of stunting and wasting among children, and high rates of iron deficiency among adult women and children alike. Cereals contribute around half the energy intake in Pakistan and wheat dominates all other cereals (Gazdar and Mysorewala 2016). The standard meal includes flat wheat flour bread or roti-cooked either on a hot plate as chapati (flat bread) or baked in a clay oven as naan (leavened bread traditionally cooked in a clay oven) - as its main starchy component. Wheat flour has, therefore, been seen as a promising vehicle for addressing anaemia through iron fortification (Gaffey et al. 2014). The high prevalence of wheat flour consumption, which makes wheat a favourable vehicle for fortification is, in fact, a sign of undernourishment - wheat flour is the cheapest source of energy. Even so, around two-fifths of the country's population consume less than 2,100 kilocalories per day (Balagamwala and Gazdar 2013). 
Hunger directly affects around one third of households. A nationally representative survey found that one tenth of households had experienced severe hunger while another 20 per cent had experienced moderate hunger (Government of Pakistan 2011).

The appeal of wheat flour fortification, evidence notwithstanding, is clear from the number of attempts at establishing fortification programmes (Zuberi, Mehmood and Gazdar 2016). There have been at least seven wheat flour fortification interventions in Pakistan - two national and five regional - since 2005. Independent evaluations are not publicly available for any of these. The largest programme was the National Wheat Flour Fortification Programme (NWFFP) led by the Global Alliance for Improved Nutrition (GAIN) with technical support from Nutrition International (NI, formerly Micronutrient Initiative). NI has been involved in one way or another in all interventions since then (MI 2015). The United Nations World Food Programme (WFP) is another key participant. At the time when fieldwork for this case study was carried out, the only operational project was a WFP and NI project in the Azad Jammu and Kashmir (AJK) region. NI is also a technical partner in the consortium, implementing an ambitious new national fortification programme supported by UK Aid (DFID 2016b).

All of the interventions follow a similar model. They work with licensed private sector flour mills to create capacity for fortification, provide the pre-mix, conduct social marketing campaigns to increase awareness about the benefits of consuming fortified flour, and lobby for the mandatory fortification of flour and for the setting up of systems of quality assurance. These are, in fact, common elements in food fortification programmes across developing countries. This article proposes to study wheat flour fortification programmes as a case study of technocratic optimism in the face of stubborn institutional constraints. We believe that the case study bears relevance for countries where comparable models of intervention have been championed or implemented, and for a broader agenda of pro-nutrition food policy reform.

Section 2 sets our framing of the case study and its methodology. Wheat flour value chains are described in Section 3, where we also anticipate issues for the design of wheat flour fortification interventions. Section 4 reports our observations from the fortification project in AJK. Case study findings are discussed in Section 5, and Section 6 concludes the article and draws out broader lessons for nutrition interventions.

\section{Framing and methodology \\ 2.1 Technocratic optimism}

'Technocratic optimism' - or the belief that there are viable technological solutions to structural problems - has been identified as a powerful driver of champions of technology-based interventions (May et al. 2003). ${ }^{1}$ An insightful study of the process of introducing a new technology into health systems speaks of 'ideation' as a level in the discourse where 'general notions about the definition and production of 
both a new technology and reliable knowledge about it are formed and circulated' (May et al. 2003: 701). The processes and actions analysed by May et al. (2003) in the context of health systems could easily apply to the role of champions such as the American Medical Association in the 1920s and 1930s (Bishai and Nalubola 2002), or The Lancet 2013 Nutrition Series (e.g. Bhutta et al. 2013) in the current discourse on food fortification. Positive but inconclusive evidence on the reduction in anaemia through food fortification (e.g. Gera, Sachdev and Boy 2012; Das et al. 2013) has been deemed 'reliable knowledge' on which to base strong advocacy for an intervention for which there is no specific evidence, viz. wheat flour fortification in countries such as Pakistan. ${ }^{2}$

Moreover, as public-private partnership models have progressively replaced government or donor-administered programmes in developing countries (Danton-Hill 1998; Yach et al. 2010), food fortification champions such as GAIN have constructed persuasive narratives that link technocratic optimism with corporate power. The linear outputoriented approach of these narratives predisposes them towards ignoring broader issues and causes of hunger and malnutrition (Kaan and Liese 2010). A fortification programme, after all, is more complex and involves coordinated actions by a range of players, than a tightly administered trial. ${ }^{3}$

\subsection{Value chains perspective}

The resistance to evidence of particular models of wheat flour fortification interventions in Pakistan and elsewhere suggests a need for broader evaluative frameworks that can make explicit some of the structural, institutional, and behavioural constraints which technocratic optimism overlooks. Although it emerged initially as a tool for business strategy, the value chains perspective gained wider applicability for an understanding of how private business might contribute to public policy goals such as nutrition. ${ }^{4} \mathrm{~A}$ value chain 'is described by the series of activities and actors along the supply chain, and what and where value is added in the chain for and by these activities and actors' (Hawkes and Ruel 2011:3).

Maestre, Poole and Henson (2017) developed a simple framework to aid the design and assessment of sustainable public-private interventions for improving the nutrition of vulnerable populations through the consumption of nutrient-dense food useful for correcting biases such as technocratic optimism. Based on an extensive review of existing literature on agri-food value chains, their framework proposes a checklist of requirements which must be met with respect to producer incentives, consumer behaviour, and coordination, for the success of an intervention:

On the consumer side, the intervention must factor in awareness about the nutritional value of the food, and needs to ensure that the food is available, acceptable in terms of tastes and cultural norms, and affordable, for the target population. 
For the intervention to be successful, the private sector must respond to incentives and be able to capture value along the value chain, and public policy must play an effective role with respect to coordination and regulation.

This system-wide view of an intervention is particularly useful for bringing perspectives from agriculture and food policy to bear on nutrition interventions which tend to be driven by health programming. We, therefore, use the Maestre et al. (2017) framework to map elements of the wheat flour value chain in Pakistan - including producer incentives, consumer behaviour, and regulatory governance - to place the generic model of the wheat flour fortification intervention in its broader institutional context. We probe whether and to what extent this intervention fulfils the requirements set out in Maestre et al. (2017), technocratic expectations notwithstanding.

\subsection{Methodology}

We draw on three sources to trace the wheat flour value chain in Pakistan: existing studies and reviews of the wheat sector and fortification projects; a representative sample survey of consumers in (wheat-growing) rural areas of Sindh Province; and qualitative fieldwork including interviews with stakeholders with interests along the value chain including policymakers, project implementers, farmers, millers, wholesalers, retailers, and consumers. ${ }^{5}$ Community-level qualitative research was carried out to understand consumer behaviour and preferences, and producer incentives. We conducted in-depth household interviews to probe factors behind consumer (and producer) choices with respect to the acquisition, storage, and use of wheat and wheat flour.

Three types of sites were purposively selected. First, we visited rural communities in a wheat-growing region of Sindh Province to understand both the producer end of the value chain as well as consumption patterns in a setting where locally produced wheat was in abundant supply. Second, low- to middle-income localities in the metropolis of Karachi were selected to gain insights into consumer behaviour in a market-dominated setting. Third, we wanted to observe a wheat flour fortification project at work. The only opportunity at the time of the fieldwork was in the region of AJK which had an ongoing fortification programme. We had aimed to interview informants in rural as well as urban areas in that region but were unable to visit rural sites due to security considerations. The main respondents in these communities were women and men in households with young children who were interviewed about any interaction they had with the wheat value chain - as producers and consumers. Although all our survey sites were relatively low-income communities, we took care to ensure that our respondents included the more marginalised individuals and households as well as the somewhat better-off ones. 


\section{Wheat flour value chains}

\subsection{Grain to flour}

Pakistan grows around 23 million tonnes of wheat annually and domestic output is sufficient, in most years, to satisfy consumer demand (Pakistan, Ministry of National Food Security and Research 2014-15). Wheat is grown across the country, particularly in the irrigated plains of Punjab and Sindh which account for around nine-tenths of the total harvest (ibid.). The government occupies a strategic position in a sector otherwise dominated by the private sector. At harvest time, its procurement agencies - notably provincial food departments - purchase around a quarter of the crop at an officially designated support price. Government stock is subsequently sold to private mills at subsidised prices. The government's involvement in the wheat economy is seen as the main plank of the country's food security policy, which revolves around ensuring domestic stocks of wheat and preventing shortages and price spirals in urban markets (Gazdar 2015).

There is no precise data about other uses of the crop, but it is estimated that private traders and mills directly buy between 15 and 19 per cent of the harvest. Farmers are, therefore, thought to retain over 60 per cent of the harvest in the first instance. Only around half that amount is kept for self-consumption or seed. The rest is either used as in-kind payments (including to harvest labourers), or sold to private sector buyers. ${ }^{6}$

\subsubsection{Alternative value chains: chakkis and mills}

There are two alternate value chains for producing wheat flour: small-scale, traditional, community-level chakkis and large-scale flour mills spread across the country. Virtually all the grain which does not enter the market, such as that which is retained for self-consumption by farmers or is earned by labourers as in-kind payment, goes through a local chakki. For grain that customers bring for grinding, the chakki charges a small fee. The chakki system is the predominant value chain in wheat-growing rural areas of Punjab and Sindh, by which grain is crushed into wholewheat flour. ${ }^{7}$ Chakkis are not limited to rural areas; they are common in cities too. Chakkis also buy grain from the market, which is particularly the case in urban areas where customers do not, typically, have their own grain stores.

The second method is processing through large-scale flour mills spread across the country. These mills acquire grain from two sources. Licensed mills are supplied grain from government stocks at subsidised prices, and they are also free to buy grain from the open market. Nearly all of the grain procured by the government eventually ends up being processed in a licensed flour mill. Mills produce a range of varieties of flour from 'regular' to 'fine' qualities.

The relationship between government agencies (primarily the provincial food department) and privately owned licensed flour mills currently revolves around three parameters. One, mills are assigned quotas according to their processing capacities and their supply of government-procured grain is determined by this quota. Two, a mill 
is obliged to produce a requisite quantity of regular flour against the supply of grain. Three, the ex-mill price of regular flour, whether it is made from government-supplied grain or grain acquired from the market, is agreed between the government and the mills association. ${ }^{8}$ This price is set by taking into account processing costs and other margins which are negotiated between the millers and the government. Industry sources claim that while all atta (flour) is subject to the food department's price regulation, 'fine' qualities with low bran content (or maida) are not. The average price of the all-purpose maida flour in 2016 was anywhere between 7 and 47 per cent higher than the price of regular flour in the same market. This price differential suggests that there might be incentives for the mills to divert some of their allocation of subsidised grain towards maida production.

\subsection{Wheat economy of households}

\subsubsection{Wheat-growing rural region}

Our sample survey of households in rural Sindh provided insights into consumption patterns in wheat-producing areas. Of the 939 households that reported using wheat flour roti as their main staple food, around two thirds had some grain from the harvest - either from their crop, or as in-kind payment for work done. But only 18 per cent had sufficient grain to last them the whole year. Others either bought grain to take to chakkis or bought flour. Nearly three-fifths of the wheat-consuming households in our sample (59 per cent) worried about not having enough food to eat. A third of the households reported that adults had gone to bed hungry at least once in the previous month, and in 19.3 per cent of the households even children had slept hungry in the last month.

During in-depth interviews in the wheat-growing region, the issue of quality came up in most conversations about different sources of flour. The experience of Raheela, whose family does not own land but receives grain for wages, was fairly typical:

We get compensated with wheat grain for our labour. We use one maund [a unit of weight, equal to about $40 \mathrm{~kg}$ ] every five or six days - we have a big family. When there is no work, we end up buying sarkari [government] flour from the local shop. The shop doesn't keep chakki flour. We prefer chakki flour - we don't like the consistency of milled flour. It feels like chewing gum and is sometimes white and at other times black, and causes stomach aches. (Raheela, age 27, Naushero Feroze District) ${ }^{9}$

Although mills can produce atta using either government or privately acquired grain, most respondents mill flour with the government system. Besides perceptions about quality in terms of freshness and adulteration, consumers in the wheat-growing area also expressed their preference for freshly ground chakki flour, referring to its nutritional value:

There is 'strength' in the real [pure] grain, not in the factory-milled flour which is mixed with other stuff. We prefer getting and storing grain to flour, because we get it crushed as needed. We like fresh flour. Grain has its own vitamins, but loose flour is adulterated. (Hamid, age 40, Naushero Feroze District) 


\subsubsection{Urban areas}

We were surprised to find a strong preference for chakki flour in both of the Karachi fieldwork sites. In Azam Basti, along with factory-milled flour, a local chakki was also a main source of flour - and unlike communities in the wheat-growing areas, chakki flour was available all year round.

My husband brings $5 \mathrm{~kg}$ of wheat which lasts a week. We make chapati. The shop is close by. Chakki flour is fresh and healthier. Flour from the mills is often stale. (Saima, age 36, Azam Basti, Karachi)

Bhittaiabad, by contrast, has stronger rural linkages, as many of its residents are recent rural-urban migrants. Residents brought grain from their villages to the city and used a local chakki much in the same way as their rural counterparts - that is, to grind their own grain.

We buy wheat from our village in Sindh and bring it over by bus. My husband or some other family member who visits the village brings it with them. We bring 40-60kg, and grind $25 \mathrm{~kg}$ at a time. This lasts us a month. We don't have our own land but our village has a lot of wheat so my husband buys it at harvest time. The flour made from this wheat tastes good, and its roti has a nice colour. We don't buy milled flour. Our own wheat is better. (Huma, age 25, Bhittaiabad, Karachi)

Like their rural counterparts, many in Bhittaiabad are unable to stock up enough grain to last them the whole year. They need to rely on alternatives. Some opt for milled flour because it is cheaper than that from the chakki. Interviews with other informants in Karachi, including shopkeepers, confirm the availability of various types of flour - chakki as well as different grades of milled flour.

In the city of Muzaffarabad in AJK, we did not come across chakkis or chakki flour. This region does not have very much wheat cultivation and relies on milled flour. It is also a region where a wheat flour fortification initiative is currently active, with the claim that local mills (nearly all of which depend on government-supplied grain) are part of the programme. While most households we interviewed bought industrially milled flour, none were aware of the availability or benefits of fortified flour. 'Fine' flour (maida) is popular here and we were told that regular coarse flour, known in this area as 'red flour', is considered to be an inferior product and is consumed mostly by urban poor people and rural households. Some of the reasons for the unpopularity of mill atta here are similar to those in the wheat-growing region. It is suspected that red flour is made from poor quality grain and contains adulterants and impurities.

\subsection{Issues highlighted for wheat flour fortification interventions}

Past, current, and planned fortification interventions in Pakistan share one essential feature: they work with the industrial mill segment of the wheat flour value chain. This is in line with the view of influential international organisations that regard industrially milled flour as 'fortifiable' (WHO et al. 2009). ${ }^{10}$ These organisations recommend fortification as a viable strategy in countries where a large proportion of 
the flour that is consumed is milled industrially. Moreover, fortification interventions in Pakistan seek to leverage existing public-private partnership between government (mostly provincial food departments) and licensed mills which are members of the Pakistan Flour Mills Association (PFMA). Our review of the wheat flour value chain reveals a number of institutional issues that are pertinent to the viability and success of wheat flour fortification interventions.

\subsubsection{Data gaps}

First, there are significant gaps in the data on key aspects of the wheat economy. While the PFMA website (PFMA 2016) reports a total of 915 mills across the country, other sources give divergent numbers. ${ }^{11}$ The mills association publishes data on the aggregate milling capacity of its members, but no data are available on their utilisation of grain or their output of atta or maida. Gaffey et al. (2014) assert that around half of all households acquire their flour from the mills without citing a source. A key informant from an international non-governmental organisation (INGO) involved in a fortification programme was of the view that mills account for around 60 per cent of all flour consumed in the country. Other sources speculate that mills cater to the consumption needs of around 40 per cent of the population (Prikhodko and Zrilyi 2013). There is no precise data on the number of chakkis either - estimates range from 6,000 (a key informant from an INGO), 7,925 (a representative of the PFMA, Awan 2015) to 30,000 (Gaffey et al. 2014).

\subsubsection{Consumer constraints and choices}

Second, factors which determine the availability and consumption of fortifiable flour in preference to its alternatives vary across income groups and regions. For many of the poorest, the most salient nutritional issue is the acquisition of sufficient amounts of flour or bread to stave off hunger. But even families, such as that of Raheela mentioned previously, who opt for the cheapest alternative available, have a clear preference for particular types of flour. Rural consumers in wheat-growing areas, as well as urban migrants from those areas, prefer freshly ground chakki flour for its texture, taste, and the perception of 'goodness'. In non-wheat-growing areas and urban centres that have historically relied on milled flour (made from government issued wheat), coarse flour is considered to be an inferior product and the more expensive 'fine' flour (maida) is associated with upward mobility.

There is a seasonal element in the availability of different types of flour in the various regions. Wheat is harvested from March to May, and consumers in the wheat-growing regions maintain post-harvest stocks which last them several months. From around January onwards, most rural households rely on the market for their flour - either on local chakkis which have their own grain stores or on mill flour. The formal value chain around the larger flour mills also operates seasonally. While government procurement operations take place at harvest time, supplies from this stock begin only from around September and carry on until the next harvest. The availability of different grades of mill flour also varies seasonally and by region. 


\subsubsection{Prices and efficiency}

Third, the wheat procurement and supply system has given rise to several types of inefficiencies. The government ends up with a virtual monopoly in the stock of wheat grain in most wheat-deficit areas. According to a Food and Agriculture Organization of the United Nations (FAO) study (Prikhodko and Zrilyi 2013), there is little incentive for the private sector to invest in storage capacity if the government is expected to subsidise the cost of holding stocks. Licensed private sector mills are then allocated quotas of subsidised grain from government stocks. The quotas are determined by mill size and this accounts for overinvestment in or over-reporting of milling capacity (Dorosh and Salam 2008). Prikhodko and Zrilyi (2013) estimate that the issue price of wheat to flour mills includes a subsidy element of around 15 per cent. The retail price of chakki flour, however, is only around 10 per cent higher than mill atta, and it remains competitive despite the industrial scale and public subsidy enjoyed by the modern value chain.

\subsubsection{Regulatory weaknesses}

The observations above point to regulatory weaknesses in the wheat economy, particularly in the relationship between government and mills. The absence of precise data on key aspects of the value chain underlines the lack of transparency in the utilisation of the public subsidy. Negative consumer perceptions about mill atta point to inadequate incentives and sanctions to ensure quality. The system has introduced costly distortions, and is unable to pass on the benefit of subsidies and industrial scale to consumers. Wheat fortification interventions seek to leverage existing public-private partnerships in a segment of the wheat flour value chain which is beset with regulatory lapses.

\section{Fortification programmes \\ 4.1 Fieldwork findings in Azad Jammu and Kashmir}

There are 11 licensed flour mills in AJK, and apart from two mills in Mirpur which have special permission to buy some grain privately from Punjab Province, all of them rely exclusively on government-supplied grain. The mills are NI partners and, as such, have agreed to produce only fortified flour. ${ }^{12}$ Fortified flour is available with retailers who act as licensed dealers. Other shops do not stock it. Most of the stores we visited, however, stocked flour from mills located in Punjab or elsewhere. We found only one licensed depot across Muzaffarabad and did not find fortified flour in any other retail outlet. Some shops stocked a local brand which had the tagline 'full of nutrition' on the packaging, but there was no specific mention of fortification on the bag. ${ }^{13}$ According to millers and wholesalers, rural poor people end up buying the fortified flour not because they know it is fortified but because they are constrained to buying the cheaper 'red' flour which happens to be fortified. ${ }^{14}$

At the one licensed depot that we found, the shopkeeper said he had little incentive to sell or keep fortified flour as it had a very small margin for him. He said that a $40 \mathrm{~kg}$ bag of flour - whether it was fortified or not - sold for 1,500 rupees. He bought fortified flour for 1,486 rupees, 
but could get non-fortified flour (from Punjab mills) for 1,360 rupees. Consumers, including those living close to the licensed depot were unaware of any fortification initiative.

It might be argued that constraints to the successful implementation of the NI project in AJK were partly related to the nature of the region itself. While the high level of reliance of AJK mills on governmentsupplied wheat from outside the region made AJK a good candidate for fortification, the fact that flour could be brought in easily from other non-fortification regions, also made the uptake of fortified flour more challenging. We believe, however, that our analysis of the wheat flour value chain as well as findings from AJK do have lessons for future interventions.

\subsection{Current fortification plans}

A new national-level plan for wheat flour fortification was initiated in 2016 with a grant from UK Aid. This project is to be implemented by a consortium of organisations (including NI) in partnership with provincial and federal governments. The wheat flour fortification element of this project is similar in some ways to past initiatives. The project aims to work with licensed flour mills and the PFMA to provide feeders, pre-mix, and training for flour fortification. The main lesson from past projects which is reflected in the initial thinking about programme design is the need for prior attention to mandatory fortification in the provinces, and the setting up of quality checking and enforcement mechanisms on the ground. ${ }^{15}$

\section{Discussion}

Technocratic optimism around the reduction in anaemia through wheat flour fortification is based on a number of assumptions about consumer behaviour, producer incentives, and regulatory action that appear to be unrealistic. There are questions about whether or to what extent the simple checklist of pro-nutrition value chains actions and processes identified by Maestre et al. (2017) are met by the generic design of flour fortification programmes that has shown resilience in Pakistan.

The availability of fortified flour to the target population is not simply an unresolved issue with respect to the relative size of the chakki value chain which is not subject to any of the fortification programmes. There are seasonal variations in the operation of industrial mills as well across different parts of the country. Existing evidence on the acceptability of fortified flour (e.g. Mahmood, Zeb and Khan 2007), is based on the blind testing of specially prepared batches of flour which are identical except for the addition of fortificants. A more realistic comparison will include the range of products of different qualities that are actually available to consumers across seasons and locations. The impact of wheat flour fortification on outcomes such as anaemia has been difficult enough to establish empirically under conditions where there is high and consistent exposure to fortified flour (Hurrell et al. 2010). It is likely to be considerably harder to show in a population where a large segment does not consistently consume fortified flour. 
There are critical issues with respect to producer incentives and regulation. The AJK fieldwork reiterated regulatory weakness in the government-mills relationship as, perhaps, a basic institutional constraint which has ramifications not only for the quantity and outreach of fortifiable flour, but also on consumer perceptions about its quality. Mandatory fortification backed up by effective quality checking has been proposed as a solution to such problems (Gaffey et al. 2014). It is questionable, however, whether a technical response is sufficient to turn things around in an entire segment of the industry that has evolved around the capture, not of entrepreneurial rent (as envisaged in the value chains perspective), but of public subsidy.

\section{Conclusion}

Wheat is perhaps the most important food crop in the country, and being the main source of energy for large segments of the population, it occupies a central place in food security and nutrition policies. The government has a strategic position in the wheat flour value chain, even though private sector stakeholders are responsible for virtually all of the wheat grown and processed in the country. The persistence of felt as well as hidden hunger suggests that the existing system has failed to ensure food security for the population, even if it does prevent shortages and price spirals in urban markets. The system has, however, spawned inefficiencies, regulatory failures, and rent capture. Nutrition interventions such as wheat flour fortification need to be part of a broader reform agenda that has food security as its central objective.

Given the depth of the nutrition deficit in Pakistan, the delivery of essential nutrients through the fortification of a widely consumed staple food will remain an attractive proposition. The scientific and technical aspects of intervention design need to be seen alongside a range of factors which shape consumer behaviour and producer incentives. Fortification interventions that are not attentive to institutional constraints that perpetuate inefficiencies along the value chain are not likely to deliver on their potential. Will engagement with these arrangements lead to an unwitting endorsement of regulatory weakness and rent-seeking opportunity, or can it be used as a lever for much needed reform?

Wheat flour fortification and other food fortification initiatives across the globe are sustained, in part, by technocratic optimism which need to be corrected using other evaluative frameworks such as those offered by the value chains perspective. The possibility of the involvement of the business sector through public-private partnerships tends to magnify this optimism by holding out the prospect of commercial viability and long-term sustainability. The core narrative is appealing, indeed, as it combines the apparent certainty of science with the logic of the market. This case study of wheat flour fortification interventions in Pakistan is a cautionary tale that highlights some costs of ignoring process for output. It calls for taking a step back and asking whether existing public-private partnerships in the sector where the intervention is sought are ready for institutional reform. 


\section{Notes}

1 Technocratic optimism has been shown to affect expert opinion and decision-making in a number of spheres (e.g. Clark, Robert and Hampton 2016), and is thought to be stronger among specialised experts in a given field compared with individuals with broader areas of expertise (Tichy 2004).

2 In fact, as Bishai and Nalubola (2002) show, following the success of salt iodisation in eliminating goitre in the US Midwest in the 1920s, the championing of other forms of food fortification (notably that of wheat flour and bread with iron) was based on technocratic optimism rather than specific evidence of impact.

3 Evidence of positive impact of flour fortification programmes is, understandably, even more ambivalent than that based on trials (Hurrell et al. 2010; Pachón et al. 2015).

4 A brief account of how the value chains perspective evolved with respect to nutrition is offered in the accompanying case study on the dairy sector in Pakistan in this issue (see Ansari et al., this IDS Bulletin).

5 The Women's Work and Nutrition survey undertaken for LANSA in collaboration with the Collective for Social Science Research and the Leverhulme Center for Integrative Research on Agriculture and included modules related to the consumption end of wheat flour.

6 These aggregate harvest shares are based on Dorosh and Salam (2008), who in turn, base their estimates on a survey of farmers in Punjab and Sindh in the late 1990s.

7 Key informant interview, sector expert, Islamabad. Bran content of flour produced by chakkis cannot be extracted.

8 While the ex-mill price is regulated by the provincial food department, wholesale and retail price regulation comes within the domain of other market regulation authorities in most areas.

9 The community-level fieldwork interviews cited in this article took place 13-30 May 2016.

10 Designating industrially milled flour as 'fortifiable' is to do with the available fortification technologies rather than the milling process itself.

11 Gaffey et al. (2014) record 1,200 mills, and the logframe of DFID's (UK Department for International Development, also UK Aid) food fortification project in Pakistan (DFID 2016a) notes a total of 1,202 licensed mills. A 2015 presentation by an expert associated with the PFMA claims that there were 1,575 mills registered with the association (Awan 2015).

12 According to the programme director, the choice of AJK for the MI fortification project was partly motivated by the fact that the region has a high proportion of fortifiable wheat, and that there is greater government control over the supply of grain (Naqash 2015).

13 It was surprising, given the claim that all local mills relied exclusively on government-supplied grain, that this AJK mill produced flour other than the regular fortified variety.

14 In the rural localities close to Muzaffarabad that we visited, retailers did not report stocking fortified 'red' flour. We were unable to visit more remote rural areas due to security-related travel restrictions. 
15 Gaffey et al. (2014) draw this lesson from the unpublished evaluation of an earlier national wheat flour fortification project.

\section{References}

Awan, M.T.S. (2015) Wheat Flour Fortification Status in Pakistan and Entrepreneurial Approaches, www.slideshare.net/tariqsarwqarawan/ wheat-flour-fortification-status-in-pakistan-and-entrepreneurialapproaches (accessed 10 March 2017)

Balagamwala, M. and Gazdar, H. (2013) 'Agriculture and Nutrition in Pakistan: Pathways and Disconnects', IDS Bulletin 44.3: 66-74, http://bulletin.ids.ac.uk/idsbo/article/view/236 (accessed 13 October 2017)

Bhutta, Z.A. et al. (2013) 'Evidence-Based Interventions for Improvement of Maternal and Child Nutrition: What Can Be Done and at What Cost?', The Lancet 382.9890: 452-57, http://dx.doi.org/10.1016/ S0140-6736(13)60996-4 (accessed 7 November 2017)

Bishai, D. and Nalubola, R. (2002) 'The History of Food Fortification in the United States: Its Relevance for Current Fortification Efforts in Developing Countries', Economic Development and Cultural Change 51.1: $37-53$

Clark, B.B.; Robert, C. and Hampton, S.A. (2016) 'The Technology Effect: How Perceptions of Technology Drive Excessive Optimism', Fournal of Business and Psychology 31.1: 87-102, https://doi.org/10.1007/s10869-015-9399-4 (accessed 7 November 2017)

Danton-Hill, I. (1998) 'Overview: Rationale and Elements of a Successful Food-Fortification Programme', Food and Nutrition Bulletin 19.2: 92-100

Das, J.K.; Salam, R.A.; Kumar, R. and Bhutta, Z.A. (2013)

'Micronutrient Fortification of Food and its Impact on Woman and Child Health: A Systematic Review', Systematic Reviews 2: 67, doi:10.1186/2046-4053-2-67 (accessed 7 November 2017)

DFID (2016a) Logical Framework - 204023, Supporting Nutrition in Pakistan (SNIP), https://devtracker.dfid.gov.uk/projects/GB-1204023/documents (accessed 7 March 2017)

DFID (2016b) Terms of Reference for the Food Fortification Component of the Supporting Nutrition in Pakistan Programme, Supporting Nutrition in Pakistan (SNIP), www.contractsfinder.service.gov.uk/Notice/ b9978272-c841-40ec-8b52-4bb953d2fbc0 (accessed 7 March 2017)

Dorosh, P. and Salam, A. (2008) 'Wheat Markets and Price Stabilisation in Pakistan: An Analysis of Policy Options', The Pakistan Development Review 47.1: 16

Gaffey, M. et al. (2014) Pakistan Food Fortification Scoping Study, Research Report, Seattle WA: PATH

Gazdar, H. (2015) 'Food Prices and the Politics of Hunger: Beneath Market and State', IDS Bulletin 46.6: 68-75, http://bulletin.ids. ac.uk/idsbo/article/view/51 (accessed 13 October 2017)

Gazdar, H. and Mysorewala, A. (2016) Large Surveys and Small Voices: Meanings of Hunger in Pakistan, Joint Agency Research Report, Brighton: IDS and Oxfam International 
Gera, T.; Sachdev, H.S. and Boy, E. (2012) 'Effect of Iron-Fortified Foods on Hematologic and Biological Outcomes: Systematic Review of Randomized Controlled Trials', American fournal of Clinical Nutrition 96.2: 309-24, doi:10.3945/ajcn.111.031500 (accessed 7 November 2017)

Government of Pakistan (2011) National Nutrition Survey 2011, conducted by Agha Khan University, Agha Khan: UNICEF

Hawkes, C. and Ruel, M.T. (2011) Value Chains for Nutrition, paper 4 prepared for the IFPRI 2020 International Conference 'Leveraging Agriculture for Improving Nutrition and Health', New Delhi, India, 10-12 February

Hurrell, R. et al. (2010) 'Revised Recommendations for Iron Fortification of Wheat Flour and an Evaluation of the Expected Impact of Current National Wheat Flour Fortification Programs', Food and Nutrition Bulletin 31.1 (supplement)

Kaan, C. and Liese, A. (2010) 'Public Private Partnerships in Global Food Governance: Business Engagement and Legitimacy in the Global Fight Against Hunger and Malnutrition', Agriculture and Human Values 28.3: 385-99

Maestre, M.; Poole, N. and Henson, S. (2017) 'Assessing Food Value Chain Pathways, Linkages and Impacts for Better Nutrition of Vulnerable Groups', Food Policy 68: 31-39

Mahmood, F.; Zeb, A. and Khan, N. (2007) 'Comparative Acceptability Studies on Roller-Milled Wheat Flour Fortified with Three Different Iron Fortificants in Pakistan', poster presented at Micronutrient Forum: Consequences and Control of Micronutrient Deficiencies, Istanbul, Turkey, 16-18 April

May, C.; Mort, M.; Williams, T.; Mair, F. and Gask, L. (2003) 'Health Technology Assessment in its Local Contexts: Studies of Telehealthcare', Social Science \& Medicine 57.4, doi:10.1016/S02779536(02)00419-7 (accessed 7 November 2017)

MI (2015) 'MI Experience in Pakistan', internal Micronutrient Initiative document

Naqash, T. (2015) 'Wheat Flour Fortification Project Launched in AJK', $D A W \mathcal{N}, 9$ June, www.dawn.com/news/1187086 (accessed 13 October 2017)

Pachón, H.; Spohrer, R.; Mei, Z. and Serdula, M.K. (2015) 'Evidence of the Effectiveness of Flour Fortification Programs on Iron Status and Anemia: A Systematic Review', Nutrition Reviews 73.11: 780-95, https://doi.org/10.1093/nutrit/nuv037 (accessed 7 November 2017)

Pakistan, Ministry of National Food Security and Research (2014-15) Agricultural Statistics of Pakistan, Ministry of National Food Security and Research, www.mnfsr.gov.pk/ (accessed 3 March 2017)

PFMA (Pakistan Flour Mills Association) (2016) www.thepfma.com/ (accessed 13 February 2017)

Prikhodko, D. and Zrilyi, O. (2013) Review of the Wheat Sector and Grain Storage Issues, FAO Investment Centre, World Bank Cooperative Programme, Rome: Food and Agriculture Organization of the United Nations (FAO) 
Tichy, G. (2004) 'The Over-Optimism Among Experts in Assessment and Foresight', Technological Forecasting and Social Change 71.4: 341-63, https://doi.org/10.1016/j.techfore.2004.01.003 (accessed 7 November 2017)

WHO, FAO, UNICEF, GAIN, MI and FFI (2009) Recommendations on Wheat and Maize Flour Fortification, Geneva: World Health Organization (WHO)

Yach, D.; Feldman, Z.A.; Bradley, D.G. and Khan, M. (2010) 'Can the Food Industry Help Tackle the Growing Global Burden of Undernutrition?', American fournal of Public Health 100.6: 974-80, doi:10.2105/AJPH.2009.174359 (accessed 7 November 2017)

Zuberi, S.; Mehmood, R. and Gazdar, H. (2016) Review of Agri-Food Value Chain Interventions Aimed at Enhancing Consumption of Nutritious Food by the Poor: Pakistan, LANSA Working Paper 7, Brighton: Leveraging Agriculture for Nutrition in South Asia (LANSA) 
